\title{
Tiphaine Karsenti, Le Mythe de Troie dans le théâtre français (1562-1715)
}

Dario Cecchetti

\section{(2) OpenEdition}

Journals

\section{Edizione digitale}

URL: http://journals.openedition.org/studifrancesi/3711

DOI: 10.4000/studifrancesi.3711

ISSN: 2421-5856

\section{Editore}

Rosenberg \& Sellier

\section{Edizione cartacea}

Data di pubblicazione: 1 décembre 2012

Paginazione: 560

ISSN: 0039-2944

\section{Notizia bibliografica digitale}

Dario Cecchetti, «Tiphaine Karsenti, Le Mythe de Troie dans le théâtre français (1562-1715)», Studi

Francesi [Online], 168 (LVI | III) | 2012, online dal 30 novembre 2015, consultato il 07 mars 2021. URL: http://journals.openedition.org/studifrancesi/3711 ; DOI: https://doi.org/10.4000/studifrancesi.3711

Questo documento è stato generato automaticamente il 7 mars 2021.

\section{cc) (†) $९$}

Studi Francesi è distribuita con Licenza Creative Commons Attribuzione - Non commerciale - Non opere derivate 4.0 Internazionale. 


\title{
Tiphaine Karsenti, Le Mythe de Troie dans le théâtre français (1562-1715)
}

\author{
Dario Cecchetti
}

\section{NOTIZIA}

TIPHAINE KARSENTI, Le Mythe de Troie dans le théâtre français (1562-1715), Paris, Champion, 2012 («Lumière classique», 90), pp. 954.

1 Gli ultimi anni hanno visto un moltiplicarsi di studi concernenti la rivisitazione letteraria di miti classici. Un esempio ne sono i convegni organizzati a Gargnano ogni due anni, sotto l'egida dell'Università di Milano, da Liana Nissim e Alessandra Preda, consacrati a un personaggio mitico (Artemide, Medea, Elena di Troia, ecc.), convegni peraltro a cui ha arrecato il suo contributo anche Tiphaine Karsenti, che ora pubblica la sua monumentale thèse dottorale sul mito di Troia nel teatro francese del Cinque e Seicento. Nessun'altra fabula antica ha goduto di pari fortuna in questi due secoli e in questo teatro, anche per il ramificarsi del mito in molteplici filoni narrativi. Inoltre, nessun'altra fabula ha offerto agli autori drammatici del Rinascimento, del Barocco e del Classicismo una materia che altrettanto bene si prestasse ad affrontare le grandi problematiche di un periodo (i due secoli in cui si elabora la modernità) segnato dalla trasformazione profonda dei modelli culturali e politici francesi: giustamente $\mathrm{T}$. Karsenti ricorda come nella seconda metà del Cinquecento nascano, in certo qual modo parallelamente, il teatro e lo Stato moderni.

2 Il corpus teatrale su cui lavora l'A. sono le pièces francesi (tragedie, ma non solo) che si situano tra la nascita della tragedia francese moderna e la fine del regno di Luigi XIV, e trattano di episodi della guerra di Troia compresi tra il giudizio di Paride e la partenza dei Troiani dopo la caduta della loro città, includendo anche in questi testi quelli dedicati alla storia di Pirro e Andromaca. Il corpus suddetto comprende trentacinque pièces, anche se ne vengono menzionate alcune altre risultate irreperibili. Il piano dell'intero lavoro segue una ripartizione cronologica in funzione dell'evoluzione 
storica, politica ed estetica. Le sezioni di tale ripartizione sono le seguenti: a) il periodo delle guerre di religione (Un temps de crise morale et politique, 1562-1598, pp. 201-296); b) il periodo di Enrico IV (Après le désastre, 1600-1610, pp. 297-390); c) il periodo del ministero di Richelieu (Sous Louis XIII et Richelieu, 1624-1642, pp. 391-517); d) il periodo infine di Luigi XIV (Le siècle de Louis XIV, 1661-1715, pp. 523-820). Per quest'ultima sezione i testi sono stati raggruppati per genere. Anzitutto la tragédie parlée, o tragedia tradizionale, in cui si distinguono due gruppi di pièces: quelle in cui Troia è «lieu de déploiement pathétique et galant» e quelle in cui Troia è «lieu d'affrontement ou de combinaison des modèles». Vengono poi esaminati i testi appartenenti al genere della tragédie lyrique, ovvero i testi destinati alla mise en musique, con un approccio estremamente originale ad opere poco frequentate dalla critica, per giungere alla conclusione che «nella tragédie lyrique si sfrutta la dimensione fondatrice del mito di Troia per piegarla a profitto di una rappresentazione moderna della Storia intesa come movimento di pregresso continuo, oppure si utilizzano i personaggi troiani per mettere in scena la capacità dello spettacolo moderno a unire in un insieme coerente tutti gli strati della tradizione drammatica di cui costituisce il risultato finale». Inoltre l'A. rivolge la sua attenzione alla tragédie de collège, a quel teatro praticato nelle scuole dei gesuiti, in cui non si troveranno forse capolavori ma che ha avuto un impatto straordinario sulla formazione teatrale del Seicento.

3 Il volume di Tiphaine Karsenti risulta essere uno strumento di lavoro di eccezionale utilità. Sia per il quadro minuzioso che essa offre della trattazione del mito di Troia a partire dall'antichità classica, con una repertoriazione puntuale della letteratura grecolatina come di quella medievale; sia per l'analisi precisa delle singole pièces, anche quelle composte non da grandi autori, ma da minores, di cui vengono evidenziati tutti gli elementi utili a ricostruire l'evoluzione dei dibattiti estetici, politici ed eticoteologici di centocinquant'anni chiave della storia (e della storia culturale soprattutto) francese. 